\title{
Common Fixed Point Theorems for Nonlinear Contractive Mappings in Dislocated Metric Spaces
}

\author{
Yijie Ren, Junlei Li, and Yanrong Yu \\ Department of Mathematics, Tianjin Polytechnic University, Tianjin 300387, China \\ Correspondence should be addressed to Yanrong Yu; tjpuyyr@sina.com \\ Received 7 January 2013; Accepted 1 February 2013 \\ Academic Editor: Ru Dong Chen
}

Copyright (C) 2013 Yijie Ren et al. This is an open access article distributed under the Creative Commons Attribution License, which permits unrestricted use, distribution, and reproduction in any medium, provided the original work is properly cited.

In 1986, Matthews generalized Banach contraction mapping theorem in dislocated metric space that is a wider space than metric space. In this paper, we established common fixed point theorems for a class of contractive mappings. Our results extend the corresponding ones of other authors in dislocated metric spaces.

\section{Introduction}

Fixed point theory is an important branch of nonlinear analysis and can be used to many discipline branches, such as control theory, convex optimization, differential inclusion, and economics. Banach proved a celebrated fixed point theorem for contraction mappings in complete metric space which is one of the pivotal results of analysis. Dass and Gupta [1] generalized Banach contraction mapping in metric space. Also Rhoades [2] established a partial ordering for various definitions of contractive mapping. The concept of metric spaces, as an environmental space in fixed point theory, has been generalized in several directions. Some of such generalizations are dislocated spaces, quasimetric spaces, dislocated quasimetric spaces, and generalized quasimetric spaces. The concept of dislocated spaces is treated differently by different authors. Matthews [3] generalized Banach contraction mapping theorem in dislocated metric space. Hitzler [4] presented variants of Banach contraction principle for various modified forms of a metric space including dislocated metric space and applied them to semantic analysis of logic programs. In this context, Hitzler and Seda [5] raised some related questions on the topological aspects of dislocated metrics. In 2005, Zeyada et al. [6] generalized a fixed point theorem in dislocated quasimetric spaces. In 2008, Aage and Salunke [7] proved some results on fixed points in dislocated quasimetric space. Recently, Isufati [8] proved fixed point theorem for contractive type condition with rational expression in dislocated quasimetric space. In this paper, we study the mapping refereed by Xia Dafeng and obtained fixed point theorems in dislocated metric space. For fixed point theorems, see $[9,10]$. The following definition is introduced by Xia et al. [11].

Definition 1 (see [11]). Let $R_{+}=[0, \infty)$. Let $G_{1}: R_{+}^{2} \rightarrow R_{+}$, $G_{2}: R_{+}^{3} \rightarrow R_{+}$, satisfying the following:

(1) if $w \leq G_{1}(u, v)$, then there exists $c \in(0,1)$, such that $w \leq c \max \{u, v\}$

(2) if $w \leq G_{2}(u, v, r)$, then there exists $c \in(0,1)$, such that $w \leq c \max \{u, v, r\}$.

Theorem 2 (see [11]). Let $(X, d)$ be complete metric spaces, let $f, g: X \rightarrow X$ be continuous mappings, and for all $x, y \in X$, such that

$$
d(f(x), g(y)) \leq G_{1}(d(x, f(x)), d(y, g(y)))
$$

or

$$
d(f(x), g(y)) \leq G_{2}(d(x, y), d(x, f(x)), d(y, g(y)))
$$

then $f, g$ have a unique common fixed point. 


\section{Preliminaries}

Definition 3 (see [6]). Let $X$ be a nonempty set and let $d$ : $X \times X \rightarrow[0, \infty)$ be a function called a distance function. If for all $x, y, z \in X$,

(1) nonnegativity: $d(x, y) \geq 0$;

(2) faithful: $d(x, y)=0 \Leftrightarrow x=y$;

(3) the triangle inequality: $d(x, y) \leq d(x, z)+d(z, x)$,

So, here $d$ is a quasimetric on $X$, and $(X, d)$ is called a quasimetric space.

Definition 4 (see [6]). Let $X$ be a nonempty set and let $d$ : $X \times X \rightarrow[0, \infty)$ be a function called a distance function. If for all $x, y, z \in X$,

(1) nonnegativity: $d(x, y) \geq 0$;

(2) indistancy implies equality: $d(x, y)=0=d(y, x)$ implies $x=y$;

(3) the triangle inequality: $d(x, y) \leq d(x, z)+d(z, x)$,

so, here $d$ is called a dislocated quasimetric or $d_{q}$-metric on $X$, and $(X, d)$ is called a dislocated quasimetric space.

Definition 5 (see [6]). Let $X$ be a nonempty set and let $d$ : $X \times X \rightarrow[0, \infty)$ be a function called a distance function. If for $x, y, z \in X$,

(1) nonnegativity: $d(x, y) \geq 0$;

(2) indistancy implies equality: $d(x, y)=0=d(y, x)$ implies $x=y$;

(3) symmetry: $d(x, y)=d(y, x)$;

(4) the triangle inequality: $d(x, y) \leq d(x, z)+d(z, x)$,

so, here $d$ is called a dislocated metric or $d$-metric on $X$ and the pair $(X, d)$ is called a dislocated metric space.

Definition 6 (see [6]). A sequence $\left\{x_{n}\right\}$ in $d_{q}$-metric space (dislocated quasimetric space) $(X, d)$ is called a Cauchy sequence, if for a given $\epsilon>0$, there exists $n_{0} \in N$ such that $d\left(x_{m}, x_{n}\right)<\epsilon$ or $d\left(x_{n}, x_{m}\right)<\epsilon$; that is, $\min \left\{d\left(x_{m}, x_{n}\right), d\left(x_{n}, x_{m}\right)\right\}<\epsilon$ for all $m, n \geq n_{0}$.

Definition 7 (see [6]). A sequence $\left\{x_{n}\right\}$ in $d$-metric spaces $(X, d)$ is said to be $d$-converged to $x \in X$ provided that

$$
\lim d\left(x_{n}, x\right)=\lim d\left(x, x_{n}\right)=0 .
$$

In this case, $x$ is called a $d$-limit of $\left\{x_{n}\right\}$ and we write $x_{n} \rightarrow x$.

Definition 8 (see [6]). A $d$-metric space $(X, d)$ is called $d$ complete if every $d$-Cauchy sequence in $X$ converges with respect to $x$ in $X$.
Lemma 9. Every converging sequence in a d-metric space is a Cauchy sequence.

Proof. Let $\left\{x_{n}\right\}$ be a sequence which converges to some $x$, and let $\epsilon>0$ be arbitrarily given. Then there exists $n_{0} \in N$ with $d\left(x_{n}, x\right)<\epsilon / 2$ for all $n \geq n_{0}$. For $m, n \geq n_{0}$, then we obtain that $d\left(x_{m}, x\right)+d\left(x, x_{n}\right)<\epsilon / 2+\epsilon / 2=\epsilon$. Hence $\left\{x_{n}\right\}$ is a Cauchy sequence.

Lemma 10. Limits in dislocated metric spaces are unique.

Proof. Let $x$ and $y$ be limits of the sequence $\left\{x_{n}\right\}$. Then $d\left(x_{n}, x\right) \rightarrow 0$ and $d\left(x_{n}, y\right) \rightarrow 0$ as $n \rightarrow \infty$. By the triangle inequality of Definition 5 , we conclude that $d(x, y) \leq$ $d\left(x, x_{n}\right)+d\left(x_{n}, y\right) \rightarrow 0$ as $n \rightarrow \infty$. Hence $d(x, y)=0$ and using the properties (2) of Definition 5, we conclude that $x=y$.

Lemma 11. Limits in dislocated quasimetric spaces are unique.

Proof. Let $x$ and $y$ be limits of the sequence $\left\{x_{n}\right\}$. Then $x_{n} \rightarrow x$ and $x_{n} \rightarrow y$ as $n \rightarrow \infty$. By the triangle inequality, it follows that $d(x, y) \leq d\left(x, x_{n}\right)+d\left(x_{n}, y\right)$. As $n \rightarrow \infty$, we have $d(x, y) \leq d(x, x)+d(y, y)$. Similarly, $d(y, x) \leq d(x, x)+d(y, y)$. Hence $|d(x, y)-d(y, x)| \leq 0$; that is, $d(x, y)=d(y, x)$. Also $d(x, y) \leq d\left(x, x_{n}\right)+d\left(x_{n}, y\right) \rightarrow 0$ as $n \rightarrow \infty$. That is, $d(x, y)=0$, and $d(x, y)=d(y, x)=0$. By the property (2) of Definition 4 , we conclude that $x=y$.

Example 12. Let $X=R^{+}$. Define $d: X \times X \rightarrow R^{+}$by $d(x, y)=$ $|x-y|$. Then the pair $(X, d)$ is a dislocated metric space. We define an arbitrary sequence $\left\{x_{n}\right\}$ in $X$; if $k>N$, there exists an positive integer $N$ that satisfies $\left|x_{k}-a\right|<\epsilon / 2$. Then, for any $m, n>N$, we have $d\left(x_{n}, x_{m}\right)=\left|x_{n}-x_{m}\right| \leq\left|x_{n}-a\right|+\left|x_{m}-a\right|<$ $\epsilon / 2+\epsilon / 2=\epsilon$. Thus, $\left\{x_{n}\right\}$ is a Cauchy sequence in $X$. Also as $n \rightarrow \infty$, then $\left\{x_{n}\right\} \rightarrow \infty \in X$. Hence, every Cauchy sequence in $X$ is convergent with respect to $d$. Thus, $(X, d)$ is a complete dislocated metric space.

\section{Main Results}

In this section, now we establish that common fixed points for mapping satisfying contractive condition are proved in the frame of dislocated metric spaces.

Definition 13 (see [9]). There exist $\phi(t)$ that satisfy the condition $\phi^{\prime}$, if one lets $\phi:[0,+\infty] \rightarrow[0, \infty)$ be nondecreasing and non-negative, then $\lim \phi_{n}(t)=0$, for a given $t>0$.

Lemma 14 (see [9]). If $\phi$ satisfy the condition $\phi^{\prime}$, then $\phi(t)<t$, for a given $t>0$.

Lemma 15 (see [11]). Let $F: R_{+}^{3} \rightarrow R_{+}$, and satisfy the condition $\phi^{\prime}$; for all $u, v \geq 0$, if $u \leq F(v, v, u)$ or $u \leq F(v, u, v)$ or $u \leq F(u, v, v)$, then $u \leq \phi(v)$.

Theorem 16. Let $(X, d)$ be a complete dislocated metric space, and let $f, g: X \rightarrow X$ be self-mapping, if 
(1) either $f$ or $g$ is continuous;

(2) there exists $F$ satisfying the condition $\phi^{\prime}$, for all $x, y \in$ $X$, such that

$d(f(x), g(y)) \leq F(d(x, y), d(x, f(x)), d(y, g(y)))$,

then $f, g$ have unique common fixed points.

Proof. Let $g$ be continuous, $x_{0}$ arbitrary in $X, x_{n}, y_{n}$ the sequence of $X$, and

$$
\begin{array}{r}
x_{n}=(f g)^{n}\left(x_{0}\right)=f g\left(x_{n}-1\right), \quad y_{n}=g(f g)^{n-1}\left(x_{0}\right), \\
n=1,2, \ldots
\end{array}
$$

Obviously,

$$
\begin{array}{r}
y_{n}=g\left(x_{n}-1\right), \quad f\left(y_{n}\right)=x_{n}, \\
g f\left(y_{n}\right)=g\left(x_{n}\right)=y_{n+1}, \\
n=1,2, \ldots .
\end{array}
$$

By the given condition, we have

$$
\begin{aligned}
d\left(x_{n+1}, y_{n+1}\right)= & d\left(f g\left(x_{n}\right), g\left(x_{n}\right)\right) \\
\leq & F\left(d\left(g\left(x_{n}\right), x_{n}\right), d\left(g\left(x_{n}\right), f g\left(x_{n}\right)\right),\right. \\
& \left.d\left(x_{n}, g\left(x_{n}\right)\right)\right) .
\end{aligned}
$$

By Lemma 15, we have

$$
d\left(x_{n+1}, y_{n+1}\right) \leq \phi\left(d\left(x_{n}, g\left(x_{n}\right)\right)\right) .
$$

Also

$$
\begin{aligned}
d\left(x_{n}, g\left(x_{n}\right)\right)= & d\left(f\left(y_{n}\right), g\left(x_{n}\right)\right)=d\left(y_{n+1}, x_{n}\right) \\
\leq & F\left(d\left(y_{n}, x_{n}\right), d\left(y_{n}, f\left(y_{n}\right)\right), d\left(x_{n}, g\left(x_{n}\right)\right)\right) \\
= & F\left(d\left(y_{n}, f\left(y_{n}\right)\right), d\left(y_{n}, f\left(y_{n}\right)\right),\right. \\
& \left.d\left(x_{n}, g\left(x_{n}\right)\right)\right) .
\end{aligned}
$$

Therefore

$$
\begin{aligned}
d\left(x_{n}, g\left(x_{n}\right)\right) & =d\left(y_{n+1}, x_{n}\right) \leq \phi\left(d\left(y_{n}, f\left(y_{n}\right)\right)\right) \\
& =\phi\left(d\left(y_{n}, x_{n}\right)\right) .
\end{aligned}
$$

By Lemma 14, we have

$$
d\left(x_{n+1}, y_{n+1}\right) \leq \phi^{2}\left(d\left(x^{n}, y_{n}\right)\right)
$$

Hence, by induction, for all $n \in N$, we obtain

$$
d\left(x_{n+1}, y_{n+1}\right) \leq \phi^{2 n}\left(d\left(x_{1}, y_{1}\right)\right)=\phi^{2 n}\left(d\left(x_{1}, g\left(x_{0}\right)\right)\right) \text {. }
$$

Similarly

$$
d\left(y_{n+1}, x_{n}\right) \leq \phi^{2 n-1}\left(d\left(x_{1}, y_{1}\right)\right)=\phi^{2 n-1}\left(d\left(x_{1}, g\left(x_{0}\right)\right)\right) .
$$

If $n \geq 2$, we have

$$
\begin{aligned}
d\left(x_{n+1}, x_{n}\right) & \leq d\left(x_{n+1}, y_{n+1}\right)+d\left(y_{n+1}, x_{n}\right) \\
& \leq \phi^{2 n}\left(d\left(x_{1}, g\left(x_{0}\right)\right)\right)+\phi^{2 n-1}\left(d\left(x_{1}, g\left(x_{0}\right)\right)\right) \\
& \leq 2 \phi^{2 n-1}\left(d\left(x_{1}, g\left(x_{0}\right)\right)\right) .
\end{aligned}
$$

Note that by the condition $\phi^{\prime}$ we know, for $n, m \in N$ such that $m>n$, we have

$$
\begin{aligned}
d\left(x_{n}, x_{n+m}\right) & \\
\leq & d\left(x_{n}, x_{n+1}\right)+d\left(x_{n+1}, x_{n+2}\right)+\cdots+d\left(x_{n+m-1}, x_{n+m}\right) \\
\leq & \phi^{2 n-1}\left(d\left(x_{1}, g\left(x_{0}\right)\right)\right)+2 \phi^{2(n+1)-1}\left(d\left(x_{1}, g\left(x_{0}\right)\right)\right) \\
& +\cdots+2 \phi^{2(n+m-1)-1}\left(d\left(x_{1}, g\left(x_{0}\right)\right)\right) \\
\leq & \sum_{i=2 n-1}^{2(n+m-1)-1} \phi^{i}\left(d\left(x_{1}, g\left(x_{0}\right)\right)\right) \\
\leq & \sum_{i=2 n-1}^{\infty} \phi^{i}\left(d\left(x_{1}, g\left(x_{0}\right)\right)\right) \longrightarrow 0 .
\end{aligned}
$$

Hence, $d\left(x_{n}, x_{m}\right) \rightarrow 0$ as $m, n \rightarrow \infty$. This forces that $\left\{x_{n}\right\}$ is a Cauchy sequence in $X$. But $X$ is a completely dislocated metric space; hence, $\left\{x_{n}\right\}$ is $d$-converges. Call the $d$-limit $x_{*} \in X$. Then, $x_{n} \rightarrow x_{*}$ as $n \rightarrow \infty$. By the continuity of $g$, as $n \rightarrow \infty, y_{n}=y_{*}=g\left(x_{*}\right)$. So as $n \rightarrow \infty$, $d\left(x_{n+1}, y_{n+1}\right) \leq d\left(x_{*}, y_{*}\right) \leq 0, x_{*}$ is the fixed point of $g$.

By the given condition, we have

$$
\begin{aligned}
d\left(f\left(x_{*}\right), g\left(x_{*}\right)\right)= & d\left(f\left(x_{*}\right), x_{*}\right) \\
\leq & F\left(d\left(x_{*}, x_{*}\right), d\left(x_{*}, f\left(x_{*}\right)\right),\right. \\
& \left.\quad d\left(x_{*}, g\left(x_{*}\right)\right)\right) \\
& =F\left(0, d\left(x_{*}, f\left(x_{*}\right)\right), 0\right) .
\end{aligned}
$$

Hence, $d\left(f\left(x_{*}\right), x_{*}\right) \leq \phi(0)=0 \Rightarrow f\left(x_{*}\right)=x_{*}$, so $x_{*}$ is a common fixed point of $f, g$.

Uniqueness. Let $y_{*}$ be another common fixed point of $f, g$. Then by the given condition, we have

$$
\begin{aligned}
d\left(x_{*}, y_{*}\right) & =d\left(f\left(x_{*}\right), g\left(y_{*}\right)\right) \\
& \leq F\left(d\left(x_{*}, y_{*}\right), d\left(y_{*}, f\left(y_{*}\right)\right), d\left(x_{*}, g\left(x_{*}\right)\right)\right) \\
& =F\left(d\left(x_{*}, y_{*}\right), 0,0\right) .
\end{aligned}
$$

Since $d\left(x_{*}, y_{*}\right) \leq \phi(0)=0 \Rightarrow x_{*}=y_{*}, x_{*}$ is the unique fixed point of $f$; similarly, we prove that $x_{*}$ is also the unique fixed point of $g$. Thus the fixed point of $f, g$ is unique, and we prove the theorem. 
Theorem 17. Let $(X, d)$ be a complete dislocated metric space; and let $f, g: X \rightarrow X$ be continuous mapping, if

(1) there exists $F$ satisfying the condition $\phi^{\prime}$, for all $x, y \in$ $X$, if $x \neq y$, such that

$$
d(f(x), g(y)) \leq F(d(x, y), d(x, f(x)), d(y, g(y))),
$$

(2) there exists $x_{0} \in X$ such that $\left\{(f g)^{n}\left(x_{0}\right)\right\}$ have a condensation point, then $f, g$ have a unique common fixed point.

Proof. Let $x_{n}, y_{n}$ be the sequence of $X$, and for all $n, x_{n} \neq y_{n}$,

$$
\begin{array}{r}
x_{n}=(f g)^{n}\left(x_{0}\right)=f g\left(x_{n}-1\right), \quad y_{n}=g(f g)^{n-1}\left(x_{0}\right), \\
n=1,2, \ldots .
\end{array}
$$

Obviously,

$$
\begin{array}{r}
y_{n}=g\left(x_{n}-1\right), \quad f\left(y_{n}\right)=x_{n}, \\
g f\left(y_{n}\right)=g\left(x_{n}\right)=y_{n+1}, \\
n=1,2, \ldots .
\end{array}
$$

Suppose that $x_{*}$ is the condensation point of $\left\{x_{n}\right\}$; there exists the subsequence $\left\{x_{n_{i}}\right\}$ of $\left\{x_{n}\right\}$ such that $x_{n_{i}}=x_{*}$. Since $g$ is continuous, $\lim g\left(x_{n_{i}}\right)=g\left(x_{*}\right)=y_{*}$.

Consider

$$
\begin{aligned}
& d\left(f\left(y_{*}\right), g\left(x_{*}\right)\right) \\
& \quad=d\left(f\left(y_{*}\right), y_{*}\right) \\
& \quad \leq F\left(d\left(y_{*}, x_{*}\right), d\left(y_{*}, f\left(y_{*}\right)\right), d\left(x_{*}, g\left(x_{*}\right)\right)\right) \\
& \quad=F\left(d\left(y_{*}, x_{*}\right), d\left(y_{*}, f\left(y_{*}\right)\right), d\left(x_{*}, y_{*}\right)\right), \\
& d\left(f\left(y_{*}\right), y_{*}\right) \leq \phi\left(d\left(x_{*}, y_{*}\right)\right) \\
& \quad \Longleftrightarrow d\left(f\left(y_{*}\right), y_{*}\right)<d\left(x_{*}, y_{*}\right) .
\end{aligned}
$$

Also consider

$$
\begin{aligned}
& d\left(x_{n+1}, y_{n+1}\right) \\
& =d\left(f g\left(x_{n}\right), g\left(x_{n}\right)\right) \\
& \leq F\left(d\left(g\left(x_{n}\right), x_{n}\right), d\left(g\left(x_{n}\right), f g\left(x_{n}\right)\right), d\left(x_{n}, g\left(x_{n}\right)\right)\right) \\
& \leq \phi\left(d\left(x_{n}, g\left(x_{n}\right)\right)\right), \\
& d\left(x_{n}, g\left(x_{n}\right)\right) \\
& =d\left(f\left(y_{n}\right), g\left(x_{n}\right)\right)=d\left(y_{n+1}, x_{n}\right) \\
& \leq F\left(d\left(y_{n}, x_{n}\right), d\left(y_{n}, f\left(y_{n}\right)\right), d\left(x_{n}, g\left(x_{n}\right)\right)\right) \\
& =F\left(d\left(y_{n}, f\left(y_{n}\right)\right), d\left(y_{n}, f\left(y_{n}\right)\right), d\left(x_{n}, g\left(x_{n}\right)\right)\right) \\
& \leq \phi\left(d\left(y_{n}, f\left(y_{n}\right)\right)\right) \\
& =\phi\left(d\left(y_{n}, x_{n}\right)\right) \text {. }
\end{aligned}
$$

Thus

$$
d\left(x_{n+1}, y_{n+1}\right) \leq \phi^{2}\left(d\left(x_{n}, y_{n}\right)\right)<d\left(x_{n}, y_{n}\right) .
$$

Hence, we know that $\left\{d\left(x_{n+1}, y_{n+1}\right)\right\}$ is decreasing. Let $\lim d\left(x_{n+1}, y_{n+1}\right)=\epsilon$ and $\lim d\left(y_{n_{i}+1}, x_{n_{i}}\right)=d\left(y_{*}, x_{*}\right) \leq$ $\lim d\left(y_{n_{i}}, x_{n_{i}}\right)=\epsilon$. Since $\left\{x_{n_{i}}\right\}$ is the subsequence of $\left\{x_{n}\right\}$, we have

$$
\begin{aligned}
d\left(f\left(y_{*}\right), y_{*}\right) & =\lim d\left(f\left(y_{n_{i}+1}\right), y_{n_{i}+1}\right) \\
& =\lim \left(d\left(x_{n_{i}}, y_{n_{i}}\right)\right)=\epsilon .
\end{aligned}
$$

Hence, we conclude that $d\left(x_{*}, y_{*}\right) \leq d\left(f\left(y_{*}\right), y_{*}\right)$, a contradiction. So $x_{*}=y_{*}, y_{*}$ is the fixed point of $g$. Similarly, $y_{*}$ is the fixed point of $f$.

Uniqueness. Let $y^{\prime}$ be another common fixed point of $f, g$. Then by the given condition, we have

$$
\begin{aligned}
d\left(y_{*}, y^{\prime}\right) & =d\left(f\left(y_{*}\right), g\left(y^{\prime}\right)\right) \\
& \leq F\left(d\left(y_{*}, y^{\prime}\right), d\left(y^{\prime}, f\left(y^{\prime}\right)\right), d\left(y_{*}, g\left(y_{*}\right)\right)\right) \\
& =F\left(d\left(y_{*}, y^{\prime}\right), 0,0\right) .
\end{aligned}
$$

Since $d\left(y_{*}, y^{\prime}\right) \leq \phi(0)=0 \Rightarrow y_{*}=y^{\prime}, y_{*}$ is the unique fixed point of $f$. Similarly, we prove that $y_{*}$ is also the unique fixed point of $g$. Thus the fixed point of $f, g$ is unique.

\section{Acknowledgments}

This research was supported by NSFC Grants No: 11071279.

\section{References}

[1] B. K. Dass and S. Gupta, "An extension of Banach contraction principle through rational expression," Indian Journal of Pure and Applied Mathematics, vol. 6, no. 12, pp. 1455-1458, 1975.

[2] B. E. Rhoades, "A comparison of various definitions of contractive mappings," Transactions of the American Mathematical Society, vol. 226, pp. 257-290, 1977.

[3] S. G. Matthews, Metric domains for completeness. Technical Report 76 [Ph.D. thesis], Department of Computer Science, University of Warwick, Coventry, UK, 1986.

[4] P. Hitzler, Generalized metrices and topology in logic programming semantics [Ph.D. thesis], University College Cork, National University of Ireland, 2001.

[5] P. Hitzler and A. K. Seda, "Dislocated topologies," Journal of Electrical Engineering, vol. 51, no. 12, pp. 3-7, 2000.

[6] F. M. Zeyada, G. H. Hassan, and M. A. Ahmed, "A generalization of a fixed point theorem due to Hitzler and Seda in dislocated quasi-metric spaces," The Arabian Journal for Science and Engineering Section A, vol. 31, no. 1, pp. 111-114, 2006.

[7] C. T. Aage and J. N. Salunke, "The results on fixed points in dislocated and dislocated quasi-metric space," Applied Mathematical Sciences, vol. 2, no. 57-60, pp. 2941-2948, 2008.

[8] A. Isufati, "Fixed point theorems in dislocated quasi-metric space," Applied Mathematical Sciences, vol. 4, no. 5-8, pp. 217223,2010 
[9] R. Chen, Fixed Point Theory and Applications, National Defense Industry press, 2012.

[10] Y. Yu and D. Sheng, "On the strong convergence of an algorithm about firmly pseudo-demicontractive mappings for the split common fixed-point problem," Journal of Applied Mathematics, vol. 2012, Article ID 256930, 9 pages, 2012.

[11] D. F. Xia, M. F. Fu, and B. Jiang, "Common fixed points for two self-mappings on symmetric sets and complete metric spaces," Advances in Mathematics, vol. 36, no. 4, pp. 415-420, 2007. 


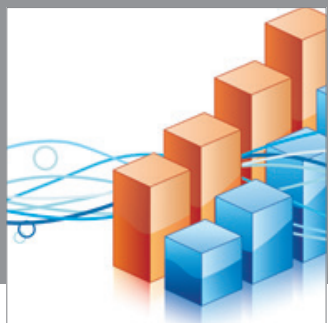

Advances in

Operations Research

mansans

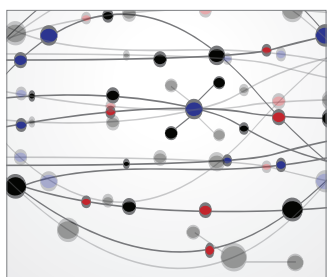

The Scientific World Journal
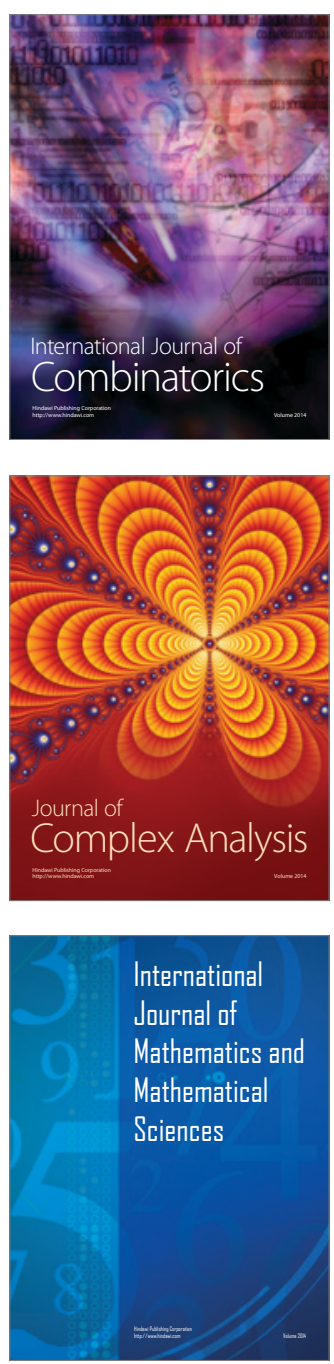
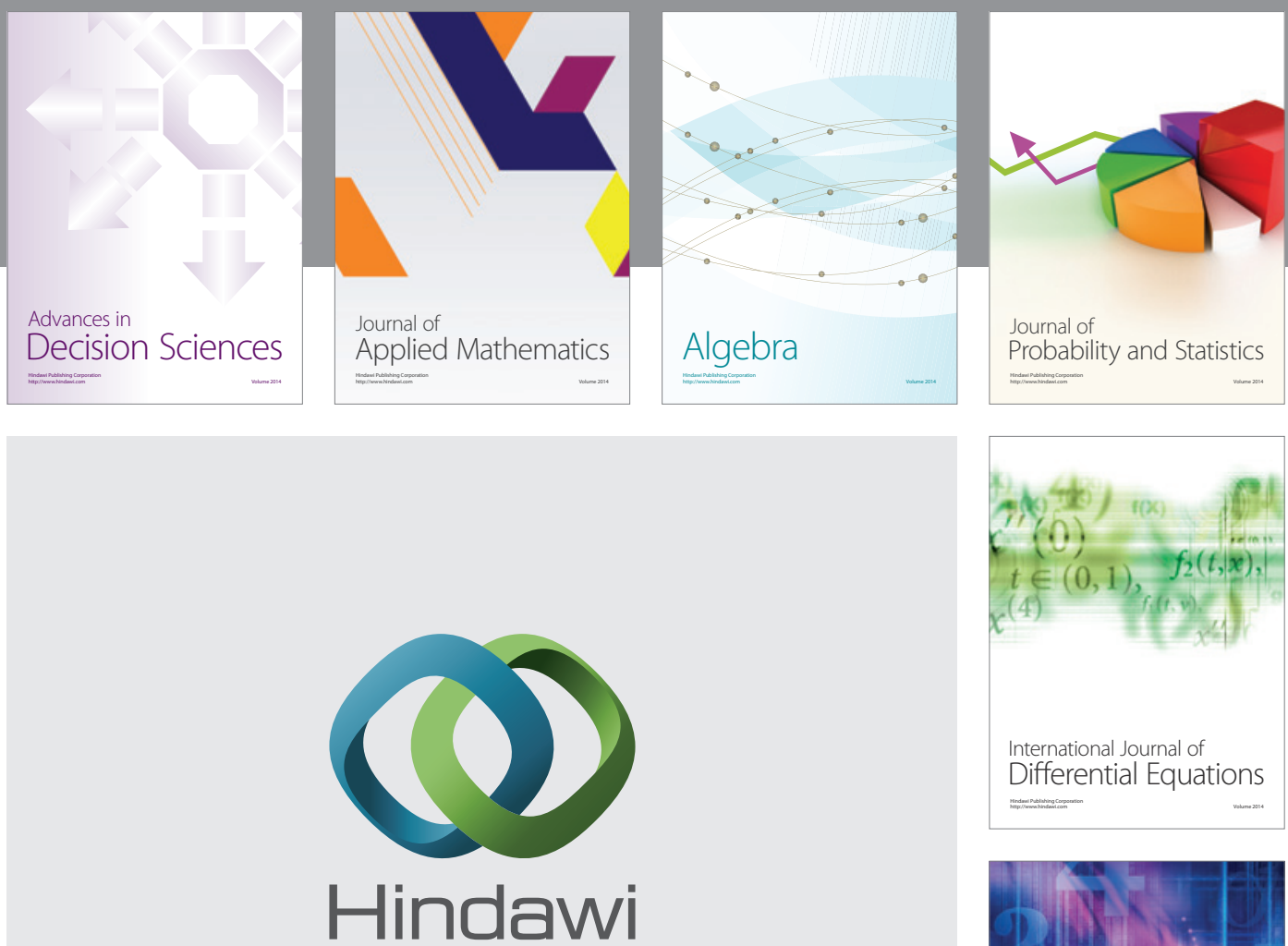

Submit your manuscripts at http://www.hindawi.com
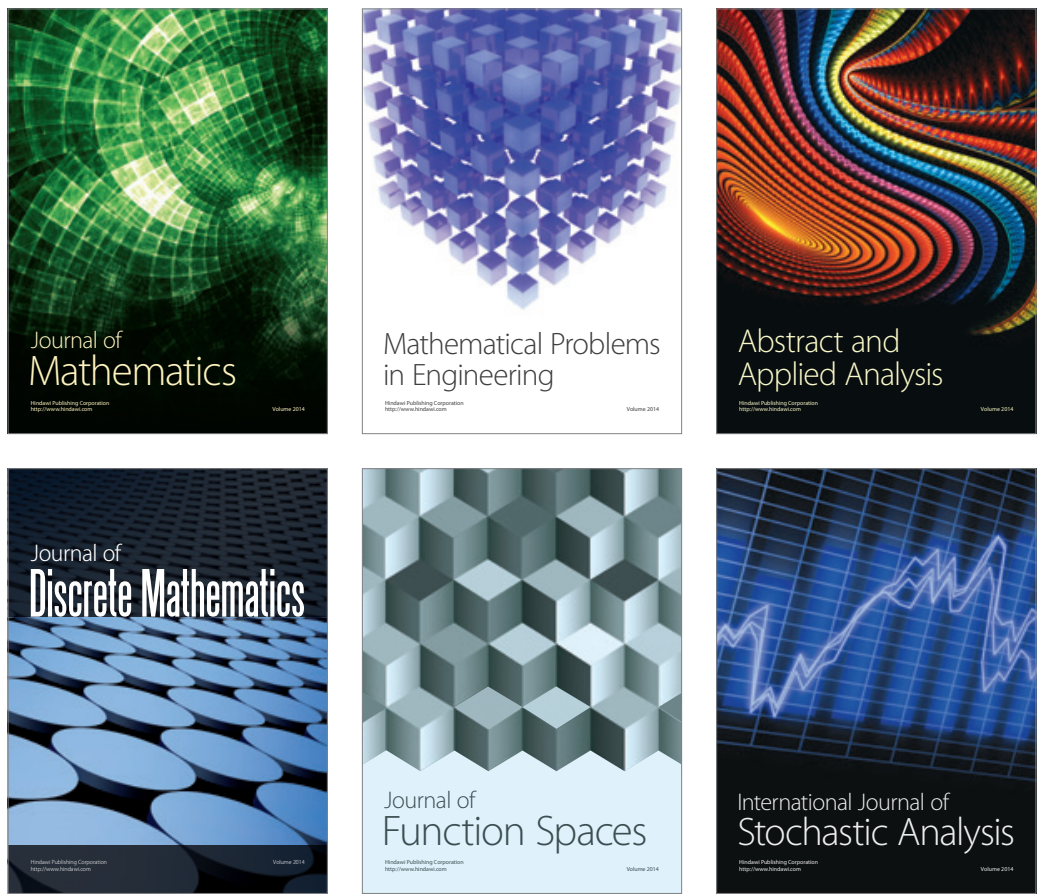

Journal of

Function Spaces

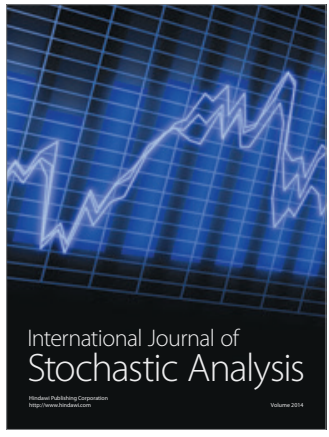

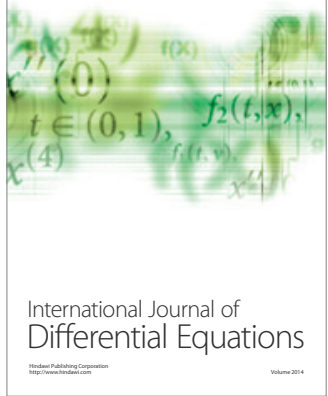
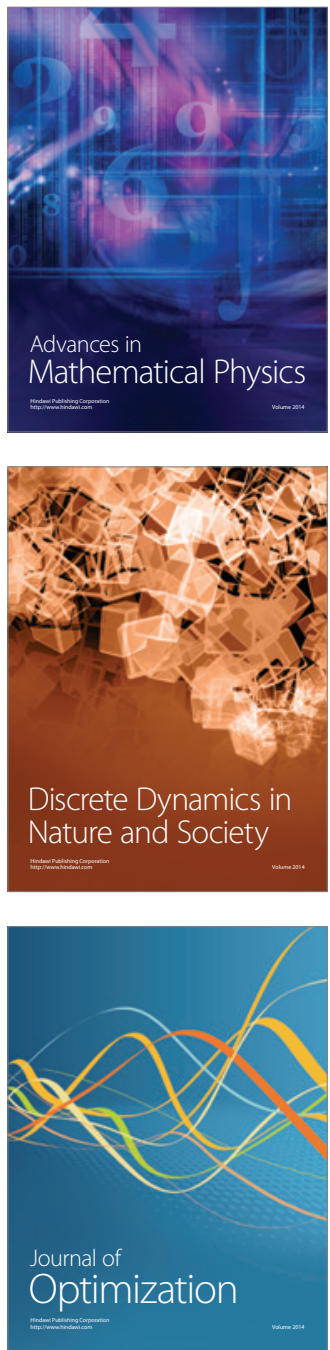